\title{
Small Tips for Treatment Principles in Coccygodynia
}

\author{
Omer ERSEN ${ }^{1}$, Serkan BILGIC ${ }^{2}$, Erbil OGUZ³ \\ ${ }^{1}$ Maresal Cakmak Military Hospital, Department of Orthopaedics, Erzurum, Turkey \\ 2GATA Haydarpasa Training Hospital, Department of Orthopaedics, Istanbul, Turkey \\ ${ }^{3}$ GATA Faculty of Medicine, Department of Orthopaedics, Ankara, Turkey
}

Dear editor,

We recently read the interesting article entitled 'Treatment Principles for Coccygodynia' by Dalbayrak et al. (3), which touches on an underrated topic in neurosurgical practice.

Periosteal preservation and closure during the coccygectomy procedure have been found to be related to the low risk of infection (2). Although Dalbayrak et al. (3) found an infection rate of $4 \%$ (one case) in their series, they did not provide information about periosteal preservation either in the surgical procedure definition or the discussion.

Caudal epidural pulsed radiofrequency treatment has been found to be effective after unsuccessful non-surgical and surgical treatment modalities in the treatment of coccygodynia and should have been mentioned in the 'Treatment Principles for Coccygodynia'. Atim et al. (1) successfully treated 5 coccygodynia patients who had experienced no remarkable improvement after surgery.

We believe that these small tips will increase the value of Dalbayrak's article (3).

\section{- REFERENCES}

1. Atim A, Ergin A, Bilgic S, Deniz S, Kurt E: Pulsed radiofrequency in the treatment of coccygodynia. Agri 23(1):1-6, 2011

2. Bilgic $S$, Kurklu $M$, Yurttas $Y$, Ozkan $H$, Oguz E, Sehirlioglu A: Coccygectomy with or without periosteal resection. Int Orthop 34(4):537-541, 2010

3. Dalbayrak S, Yaman O, Yilmaz T, Yilmaz M: Treatment principles for coccygodynia. Turk Neurosurg 24(4):532-537, 2014 